\title{
O QUE É A PSICOLOGIA?
}

\author{
Joaquim Bairrão ${ }^{1}$
}

\section{Nota Explicativa}

O presente texto apresenta a versão editada da Oração de Sapiência proferida pelo Professor Joaquim Bairrão, no âmbito das cerimónias da sua jubilação que decorreram a 23 de Novembro de 2005. Havendo disponivel uma gravação fielmente transcrita de toda a comunicação ${ }^{2}$, optámos por não reproduzi-la na íntegra, mas por compor a presente versão.

De facto, evidenciando, uma vez mais, as suas extraordinárias qualidades de comunicador, o Professor Joaquim Bairrão fez a apresentação sem o suporte de qualquer texto. Produziu uma peça oratória fascinante ajudada pela projecção de inúmeros slides sobre os quais elaborava pequenos comentários para destacar um ou outro aspecto relevante. Transcrever na integralidade o que foi dito, sem a possibilidade de restituir pela forma escrita todo o contexto audiovisual que contribuiu para dar sentido às palavras faladas, afectaria a legibilidade da comunicação. Daí a decisão de reproduzirmos a aula do professor Joaquim Bairrão sob a forma de texto editado.

Não obstante, procurámos que o texto respeitasse, na medida do possivel, a forma. Mas, mais do que a forma, preocupou-nos, essencialmente, devolver o conteúdo. Na verdade, o que ai foi transmitido reveste-se de um interesse crucial para todos aqueles que pensam a Psicologia e empenham os seus esforços no avanço desta Ciência.

Pedro Lopes dos Santos

\footnotetext{
${ }^{1}$ Professor Emérito, Faculdade de Psicologia e de Ciências da Educação, Universidade do Porto

2 Transcrição realizada por S. Barros, J. Cadima, C. Peixoto, \& H. Rosário

PSICOLOGIA, Vol. XXIII (2), 2009, Edições Colibri, Lisboa, pp. 11-20
} 
Em primeiro lugar, queria agradecer ao Sr. Vice-reitor, que representa a Universidade, pelo facto de estar aqui e pelo simbolismo das suas palavras.

Chegamos ao fim de uma carreira, em que fizemos um serviço que pensamos ter sido o melhor para os alunos e para os colegas, e é gratificante ver esse trabalho reconhecido por todos. [...] Foi extremamente agradável entrar numa sala e ouvir um não mais acabar de coisas agradáveis [...]. Nomeadamente o que disse a presidente do Conselho Directivo e as palavras do Presidente do Conselho Científico [...]. Não são coisas que se improvisam. Por mais que quisessem improvisar, não improvisaram [...]. Tudo isso torna este evento particularmente difícil!

Ora bem, dois colegas disseram-me: "Tu não faças grandes coisas, contas a tua vida, e tens a lição passada! Falas das histórias da tua vida!". Disseram-me isso, mas eu disse: " Não posso desaproveitar as conversas que tive convosco, e sobretudo os últimos anos em que trabalhámos mais de perto! [...]. Portanto, eu peço desculpa mas a conversa não vai ser só de anedotas. Vai meter um bocadinho de epistemologia, porque a Psicologia está a precisar!

Vemos na televisão alguns colegas falarem do que quer que seja, terem uma resposta para tudo e, sobretudo, pedirem às Ciências Humanas coisas que elas [...] provavelmente não podem dar. Posto isto, hesitei nas anedotas a escolher e optei por um leque que pode ser o leitmotiv para a nossa conversa.

A primeira foi quando, jovem licenciado em letras, fui parar - não sei por que carga de água - ao Centro de Investigação Pedagógica da Fundação Gulbenkian, que recrutava investigadores. Era a primeira instituição que, em Portugal, ia fazer investigação no domínio. Um dia, passava eu nos corredores com um livro debaixo do braço que se chamava Nonparametric Statistics. Um colega meu, professor de Matemática no Instituto Superior de Agronomia, disse-me então: "Ó Bairrão, para que queres tu um livro de Estatística se és de Letras?". E eu disse: "Eu sou de Letras, o que não sou é atrasado mental!".

Isto, nos finais dos anos sessenta, era paradigmático da imagem das Ciências Humanas [...]. Hoje em dia, qualquer um de nós, nesta casa, sente-se psicólogo. Mas eu não me sentia psicólogo nos anos sessenta. Primeiro, porque não tínhamos referência identitária. Segundo, porque tínhamos uns predadores chamados psicoterapeutas e psiquiatras. Em terceiro lugar, porque não sabíamos qual era o nosso espaço.

[Em termos históricos], na Europa, foi preciso esperar umas largas décadas para que houvesse uns senhores que se dissessem psicólogos seulement. Only psychologist. What you are? I'm just... only a psychologist. Ninguém era só psychologist. [...] Helmholtz era físico, Brocca neuro-anatomista, outro era linguista, etc., etc. Portanto, essa primeira identidade 
também a senti na pele e só a partir de determinada altura as pessoas se identificaram com essa profissão, que tem a ver com o tema da nossa conversa: O que é a Psicologia? Para que é que a Psicologia serve? Que Psicologia temos hoje? Quais são os grandes aforismos da Psicologia?

Uma outra anedota foi quando entrei no laboratório de Psicologia, na Faculdade de Letras de Lisboa. O meu professor de Psicologia era muito culto... em história! Um eminente historiador especializado em cartografia [...]. Mas teve o azar de ter feito um curso de seis meses nos Estados Unidos e veio com uma ideia da Psicologia um pouco curta. Então, dado dia disse-nos: "Amanhã a aula é no laboratório de Psicologia". Eu devia ter uns 18 anos. Estava na Faculdade e não pus gravata porque não era costume, mas disse lá em casa: "Amanhã vou ao laboratório de Psicologia!” O meu avô, o meu tio e o meu primo, que eram farmacêuticos, disseram: "Vê lá se te sujas!" É verdade! A família, da parte do meu pai, era toda farmacêutica, e era costume dizerem-me: "Não tomes remédio que te faz mal!" Como eles, digo igualmente: cuidado com a Psicologia, que a Psicologia às vezes também é perigosa! E no outro dia, lá fui então eu ao laboratório de Psicologia. Digo-vos exactamente o que encontrei: um crânio, que, não sei bem, devia ter vindo da Academia das Ciências, porque a Faculdade de Letras de Lisboa era na rua da Academia das Ciências. Havia um aparelho que servia aos antropólogos para medir o crânio. Havia as Tabelas de Ishihara, para ver os daltónicos, provavelmente. Havia papel de seda de várias cores, com quadradinhos, com as cores principais, para fazer o único trabalho prático que podíamos fazer naquela altura, que era analisar as cores complementares! Havia também alguns cronoscópios pré-históricos (havia um d'Arsonval, ainda havia um!), que eu nunca vi trabalhar. E havia a promessa de se ter um dia um taquistoscópio!

Então reparem, a história está a compor-se e eu agora peço desculpa porque vou ser um pouco erudito.

[...] A Psicologia - felizmente com as neurociências talvez tenhamos outra via aberta - afirmou-se como uma ciência muito pragmática e pouco científica. Como podem apreciar, Canguilhem diz coisas muito parecidas [a passagem a seguir transcrita constitui um dos slides projectados]:

Si nous ne pouvons pas définir cette psychologie par une idée de l'homme, c'est-à-dire, situer la psychologie dans la philosophie, nous n'avons pas le pouvoir, bien entendu, d'interdire à qui que ce soit de se dire psychologue et d'appeler psychologie ce qu'il fait. Mais nul ne peut davantage interdire à la philosophie de continuer à s'interroger sur le statut mal défini de la psychologie, mal défini du côté des sciences comme du côté des techniques. (Canguilhem, 1958)

[...] Os psicólogos são, assim, definidos por aquilo que fazem e não em função dos objectos que estudam ou questionam. Isto significa que o 
exercício da Psicologia não tem sido legitimado pelos fundamentos de uma verdadeira reflexão epistemológica. Lembro-me que tal ideia era, há vários anos, motivo de acesas discussões em França, às quais parece que estamos a retornar.

É bom que numa Faculdade de Psicologia - as faculdades são, por excelência, os locais onde se cultiva o avanço científico - se pense exactamente nos fundamentos desta Ciência. Nenhum físico conhecido no mundo partiu para estudar Física sem saber o que era o objecto da Física. Pelo contrário, os psicólogos lançaram-se no estudo da personalidade ou da inteligência apoiados em vagas definições, frequentemente engendradas na dependência das técnicas usadas para as medir. [Deste modo], a Psicologia foi, muitas vezes, teoricamente atípica. Aliás, nos livros americanos e ingleses é costume dizer-se this is a phase, a method or an atheoretical approach.

[...] Porque é que começámos exactamente por uma Ciência ateórica? [De facto, para corresponder a uma certa ideia de ciência], a Psicologia mimou, macaqueou a Física e as ciências naturais, usou e abusou de métodos quantitativos. Ficou extremamente contente quando pôde fazer trabalho estatístico... regressões. E importa fazê-lo, quando deve! Na mira de se libertar do seu passado filosófico, a Psicologia adoptou um empirismo que a fez deitar fora a água da banheira com o bebé lá dentro.

Daqui nasceu uma Psicologia que se contrapôs a uma outra que tem horror a números e que acha que o fenómeno psicológico ainda é hoje o vivido, o entendido, o assumido. Pierre Gréco coloca esta dualidade com grande frontalidade ao descrever a "infelicidade" do psicólogo nos seguintes termos:

C'est le malheur du psychologue: il n'est jamais sûr qu'il "fait de la science". S'il en fait il n'est jamais sûr qu'il fait de la psychologie (Gréco, 1969).

Ou seja, quando faço Psicologia, nunca sei se é Ciência. Se faço Ciência, nunca sei se é Psicologia.

Curiosamente, os psicólogos têm cada vez mais, os mesmos problemas dos filósofos. Reparem, qual é o tema avançado de Harvard ou Oxford sobre Psicologia Cognitiva: As relações mente-espírito, as relações corpo-mente. É um problema da Filosofia ou da Psicologia? Cada vez mais as duas estão juntas, têm os mesmos problemas. E mais, completam-se uma à outra em questões de natureza complicada de interface e de interdisciplinaridade. Centremo-nos, por exemplo, no problema bem real do défice da atenção que ainda ontem estive a estudar. Trata-se de um problema que está, hoje, a ser abordado por neurologistas, por psicólogos e, sobretudo, por filósofos, exactamente porque põe uma questão de raiz, que é o problema do reducionismo. Será que todo o comportamento humano se reduz à actividade 
cerebral? Ou o que é que a imanência do psicológico vai buscar à base neural?

[...] Gottlieb, num trabalho notável sobre a neuropsicologia do autismo, coloca as mesmas interrogações. Discutindo as dificuldades de auto-regulação nas crianças com desordens da família do autismo, argumenta que o problema não consiste em identificar ou descrever os eventuais correlatos neurológicos da desordem, mas sim entender o que a nível da função neuronal subjacente inibe o desencadeamento dos mecanismos cognitivos susceptíveis de serem os referenciais da conduta.

Vemos, portanto, que em múltiplos domínios começa, cada vez mais, a haver a necessidade de equipas interdisciplinares. Por exemplo, com a informação recolhida através das técnicas não invasivas, como as da tomografia computorizada ou da emissão de positrões, é possível juntar várias teorias. E aqui, o fundamental é ter boas teorias. Porque o que também está a suceder - e isso acontecerá à má Neuropsicologia, é que a Neuropsicologia irá basear-se naquilo que é a má Psicologia. Assim sendo, rapidamente adoptaremos pontos de vista que farão equivaler estados orgânicos a estados mentais. Mas aí podemos ver a importância de posições não reducionistas e mais elaboradas.

Mas porque falo eu em reducionismo? Porque estou a falar da Psicologia como Ciência, que na sua preocupação em afirmar-se como tal e no seu esquecimento de ser Ciência, passou a ser só Psicologia? Porque estou a falar do passado?

Primeiro, porque esse passado é recente. Segundo, porque esse passado é presente. E em terceiro lugar, porque, se não tomarmos em devida conta esse passado, dificilmente saberemos como ter Ciência. A Psicologia está a passar maus dias. Está a passar maus dias, exactamente porque houve como que um débito excessivo de teorias tradicionais, falta de criatividade e, sobretudo, uma ausência de reflexão sobre o que os americanos ou os ingleses chamam os fundamentals: ou seja, olhar atento às bases teóricas que, por exemplo, os físicos não deixaram por mãos alheias.

Talvez a questão dos métodos pouco importe. Enquanto alguns se vão dando conta do que há de fundamental neste mal-estar, muitos continuamos, ainda, divididos pela questão das metodologias quantitativas ou quantitativas.

A psicologia do nosso tempo está claramente em mudança, das preocupações behavioristas (a psicologia como ciência natural), que assumiu que o observável existe por si mesmo e é objecto de ciência (ciência empirica) e logo mensurável e implicando metodologias do mesmo tipo (quantitativas), a uma tendência para ultrapassar a limitada epistemologia que seguia situando-se num continuo entre um novo e um velho paradigma (Smith et al., 1996). 
Às vezes, propomos, até, métodos mistos, pensando, assim que resolvemos o problema, sem nos perguntarmos como é que chegamos aos diferentes tipos de metodologia. [Os autores acabados de transcrever] traçam as linhas que em sua opinião dividem o velho e o novo paradigma.

\section{NOVO PARADIGMA}

Compreender, descrever

Significado ou sentido

Interpretação

Linguagem, discurso, símbolo.

Holístico

Particular

Contexto cultural

Subjectividade

Smith et al., (1996)

\section{VELHO PARAGIGMA}

Medir, contar, prognosticar

Causalidade, frequência

Análise estatística

Redução a números

Atomístico

Universal

Desligado do contexto

Objectividade

Estas palavras estão separadas, mas deviam estar juntas, porque a Psicologia é as duas coisas ao mesmo tempo. É compreender, descrever, mas também é medir, contar e diagnosticar, e interpretar... São duas faces da mesma moeda, mas que nós usamos numa visão dicotómica. Quer dizer, a Psicologia ainda está eivada de uma dicotomia que dificilmente será ultrapassada ao longo do tempo.

E antes de vos recordar coisas básicas, vou-vos contar algumas coisas que me parecem importantes.

Sabem uma coisa engraçada? Quando se fala em Wilhelm Wundt, muita gente está convencida de que ele foi o pai da Psicologia Experimental. Mas ele não foi o pai. Aliás, nunca teve filhos!

Porquê esta crença generalizada? Em grande parte porque o seu nome surge incontornavelmente associado à fundação do Laboratório de Leipzig. Mas esse laboratório de Psicologia Experimental foi, apenas, uma criação semântica. Isso é-nos dito de uma maneira espantosa por um senhor chamado Sigmund Koch. Koch escreve o seguinte: "Que ciência anuncia que vai ser criada, provavelmente, por uma lápide ou pelo hastear de alguma bandeira?". Quando nasceu a Física? Ninguém sabe! Talvez algures no século II, no tempo de Aristóteles. E não consta que Aristóteles tenha dito a algum colega, talvez a Platão que passeava ali na Arcádia ou na Ágora: "olha, parece que amanhã vai haver a Física". Ou será que Heródoto teria dito: "essa coisa do Egipto está-me a cheirar mal. Acho que a gente tem mesmo que estudar aquilo. Então o melhor é criarmos a História."

Pois esta brincadeira de que vocês se estão a rir e com muita razão foi o que aconteceu com a Psicologia. A Psicologia, e o laboratório de Wundt, 
foi criado por razões de ordem sociológica. Havia realmente uma clientela à espera que a Psicologia se tornasse experimental.

Havia uns naïfs, como o senhor chamado Théodule Ribot, que tem esta frase bonita que cito de memória: "Está próxima a nova ciência, uma ciência que não se vai basear na metafísica, que não se vai basear na introspecção, naquilo que as pessoas pensam. Vai ser como as ciências biológicas, vai ser objectiva". E Koch pergunta: Será que no tempo de Ribot haveria alguém preparado [para conduzir tal empreendimento]? Qual era a formação do Wilhelm Wundt? Wundt tinha escrito uma obra de 20 volumes chamada Volkerpsychologie - para quem sabe alemão, é bonito dizer estes termos, numa assembleia destas! - que quer dizer, a Psicologia do Povo. Naquele tempo, do conjunto de cientistas "disponíveis" para trabalharem no projecto do laboratório de Leipzig, dois eram físicos, outros eram metafísicos e os restantes fisiólogos. Então, como foi Wundt criar uma nova ciência, que não existia, com gente que não existia, para fazer não sei o quê... [...] Criou um laboratório semântico e não um laboratório real. O que lá se fazia, nada tinha a ver com a Psicologia Experimental. Inclusivamente, os próprios instrumentos não existiam, a não ser alguns de determinado tipo, apropriados à medição dos tempos de reacção e pouco mais. Urgia, de facto, responder a uma expectativa e ir ao encontro dos muitos estudantes que na ânsia de conhecerem a nova ciência invadiam Leipzig. E esse número era tão grande que "obrigou" Wundt a lançar-se no empreendimento de fundar uma ciência independente e experimental. E aí começou provavelmente o nosso drama.

Não resisto, aqui, a esta frase de Ribot: "A velha ciência está possuída de um espírito metafísico, é a ciência da alma, da observação interna. A análise e o raciocínio são os processos favoritos de uma investigação, fraca e velha; ela não faz progressos e pede apenas que a deixem sossegada". Então qual é a nova ciência para Ribot? A nova Psicologia difere da velha no seu espírito. Não é metafísico (quando eles eram todos metafísicos naquele tempo), estuda apenas fenómenos e nos seus procedimentos pede de empréstimo, o mais possível às ciências biológicas. Mas, pergunto eu, o que é que são fenómenos? Ribot queria dizer provavelmente factos. E o que é um facto psicológico? Não tinha sido inventado ainda. Estavam já a fazer coisas que ainda não tinham sido inventadas.

Depois, a América aparece sempre. Com 100 laboratórios de Psicologia, com 100 alunos enviados para Leipzig, etc., teve mesmo que se arranjar uma ciência! Mas eu não estou a brincar. Só de pensar que é tão estúpido e que nunca tinha dado conta disto! Nunca me tinha dado à preocupação de ler atentamente Wundt. Já tinha lido Ribot, já tinha lido esses indivíduos todos separadamente, mas nunca os tinha lido em conjunto e nunca me dera conta de como é que tivemos uma ciência. Só pelo espantoso motivo de simplesmente a termos! 
[...] Passamos a uma nova etapa. Durante a primeira metade do século vinte emerge a ciência comportamentalista.

A ideia de uma ciência construída sobre factos replicáveis, objectivos e mensuráveis era tão forte que, ainda hoje, a praticamos em vários quadrantes. Mas esta nova ciência teve que fazer uma acrobacia, à semelhança daquela que veio substituir. Ou seja, pediu princípios de empréstimo a outros domínios do conhecimento científico. Assumiu um conceito de objectividade identificado com o directamente observável e verificável (recusando a tentação do mentalismo), adoptou o empirismo associacionista, insistiu na importância dos factores situacionais, defendeu o determinismo... Tinha, enfim, todas as características das ciências exactas e naturais, tal como o positivismo do século dezanove as concebia.

Pagou-se, igualmente, um preço caro. Ao sustentar a sua ontologia em métodos pedidos de empréstimo a outras ciências, a Psicologia ficou vulnerável a reducionismos de toda a ordem. $\mathrm{Na}$ verdade, a estrita dependência do objecto relativamente ao método possibilita que certos factos ou fenómenos psicológicos sejam redutíveis a outros níveis de explicação. Isso sucede, em grande parte, quando vemos comportamentos ou processos psicológicos explicados pelas neurociências pelo recurso à biologia ou a fenómenos de outra natureza.

Contudo, como Overton (2002) sublinha, a claridade exige que se faça uma distinção entre análise e síntese. A análise diz respeito à diferenciação das partes do todo e afasta-nos do reducionismo. Em contraste, o reducionismo implica a síntese localizada numa oposição. Mas este reducionismo, pedra de toque de um certo ideal positivista, já não podemos usar porque,

[...] Implica um corte em ciência, assentando num fundamentalismo, num materialismo e num objectivismo que era um curto passo para a formulação de uma metodologia científica completa, denominada explicação mecânica (Overton, 2002)

Há, porém, zonas de convergência pelas quais podemos entrar, não pela via do reducionismo, mas pelo caminho da conciliação. Os epistemólogos, filósofos da ciência, ou psicólogos que se interessam pela teoria da Psicologia encaram a conciliação como processo feito de análises e de sínteses que assentam numa relação dialéctica de partes e todo. Trata-se de uma busca efectuada à custa de comparações complexas.

[...] Esta tentativa de conciliação pode estender-se a posições tidas como antitéticas ou antinómicas. Como Gergen (1995) dizia, as múltiplas interpretações da experiência são legítimas e desejáveis. A total concordância dentro de um grupo pode ser ou um sinal de visões minoritárias reprimidas ou de conformidade. Nesse sentido, é preferível o conflito ao consenso, como processo de gerar conhecimento. [...] Até porque havendo questões 
objectivamente correctas e incorrectas acerca do mundo, as pessoas conceituadas poderão chegar a um comum acordo.

Enfim, eu tomo a liberdade de dizer mais a essência do conhecimento do que vos dar o próprio conhecimento. Hoje em dia, as nossas metodologias podem não se afastar tanto das metodologias objectivas, replicáveis e mensuráveis, como das metodologias qualitativas, subjectivas ou construtivistas. [...] Para tal, importa que adoptemos princípios da Metodologia Crítica. [...]. A metodologia crítica é um empreendimento criativo, complementar, de vários métodos, que funciona não pelos métodos em si, mas pelo objecto em estudo. Em função disso, é possível o uso de métodos tradicionais quantitativos, qualitativos e mistos. A metodologia crítica é uma teoria de inquirição contextual e em evolução e, portanto, pode propor-se uma progressiva clarificação, contribuindo para que se complementem evidências, se refinem argumentos ou se gerem novas assumpções persuasivas, moralmente defensáveis, internamente consistentes e susceptíveis de criar mudanças positivas ou aprender algo essencial para a experiência humana.

Moral da história: psicólogos como aqueles da televisão estão em vias de extinção. E com essa gente televisiva, me fico. Agradeço muito a vossa atenção. Peço desculpa pelo sintético da minha mensagem, mas achei que era bastante aliciante para uma assembleia como esta, que faz investigação, trazer alguns destes elementos que provavelmente serão caminhos de futuro para que consigamos ultrapassar coisas velhas e relhas que já não se podem ouvir, como o diagnóstico psicológico, como as doenças mentais, como as características psicológicas estáveis e imutáveis do indivíduo, e pensemos a partir dos problemas.

Muito obrigado pela vossa atenção.

\section{Referências}

Anglin, J. M. (1988). The science of mind: The making of cognitive science. Science, 241, 1837-1839.

Canguilhem, G. (1958). Qu'est-ce que la Psychologie. Revue de Métaphysique et de Morale, 367.

Gergen, K. J. (1995). Social construction and the educational process. In L. P. Steffe \& J. Gale (Eds.), Constructivism in education (pp. 17-39). Hillsdale, NJ: Erlbaum.

Grace, R. C. (2001). On the failure of operationism. Theory \& Psychology, 11, 5-33.

Greco, P. (1967). Épistémologie de la psychologie, In J. Piaget (Ed.), Logique et connaissance scientifique. Encyclopédie de la Pléiade, Paris.

Hibberd, F. J. (2001). Gergen's social constructionism, logical positivism and the continuity of error: Part 1: Conventionalism. Theory Psychology, 11, 297-321. 
Koch, S. (1992). Foreword: Wundt's creature at age zero-and as centenarian: Some aspects of the institutionalization of the "New Psychology". In S. Koch \& D. E. Leary (Eds.), A century of Psychology as a science. Washington, D.C.: American Psychological Association.

Overton, W. F. (2002). Understanding, explanation, and reductionism: Finding a cure for Cartesian anxiety. In L. Smith \& T. Brown (Eds.), Reductionism (pp. 29-51). Mahwah, N.J.: Lawrence Erlbaum Associates.

Smith, J. A., Harré, R., \& Langenhove, L. V. (1996). Rethinking Psychology. United Kingdom: SAGE.

Soczka, L. (2005). Contextos humanos e psicologia ambiental. Lisboa: Fundação Calouste Gulbenkian.

Yanchar, S. C., Gantt, E. E., \& Samuel L. C. (2005). On the nature of a critical methodology. Theory \& Psychology, 15, 27-50. 